\section{TREATMENT OF ANASARCA.} To the Editor of Tre LANCFT.

SiR,--In your journal of the 19 th October is a communication on Anasarea, by Dr. Witt, in which he sets forth a plan of treatment which he would apparently fain have the readers of THE LANCET think originated with himseif and his two consult. ing friends, Dr. Robertson and $\mathrm{Mr}$. Dix. I will rot dispute with Dr. Witt that the principle of the plan he describes may be quite new to the above-named gentlemen as well as to himself; but I should be very sorry to learn even from much older practitioners than myself that they have not been accustomed to have recourse to puncturing the skin of the lower extremities in cases of distress of breathing from anasarcous accumulation. It may possibly be startling to Dr. Witt to learn that I, for one, have been in the habit of (instinctively) puncturing the lower extremities, to give prompt relief in such cases, full twenty-five years of my life, with the happiest results, wbere the urgency of symptoms indicated. But my plan of puncturing differs somewhat from that described by Dr. Witt; for instead of "deeply" inserting the lancet "into the mass of cellular tissue," as he states, at two points only, I invariably make from four to ten fine punctures in each leg (if both are equally affected) by means of a small, very sharp, triangular trocar-occasionally with the lancet, when I do not happen to have the trocar with me,-fairly through the skin, but barely into the cellular tissue; when I find the fluid begins to issue freely and in sufficient quantity to relieve the distress of breathing, \&c., without fear of the patient fainting and with. ont the use of the bandages. The after-treatment consists of the application of towels or large pieces of rag, wet with hot water, to the legs, which I think preferable to a foot-bath. I have never had the least trouble with the healing of the punctures, neither have I had occasion to use adhesive plaster or bandages to them to stop the "oozing" or aid their healing. I endeavour to maintain the oozing while other means are being used for the relief of the primary disease. By the way, I may here mention, as a somewhat analogous proceeding, that I have had recourse to puncturing and applying the hot wet cloths afterwards in cases of cellular erysipelas, and find that I have seldom to treat a case of sloughing phlegmon, if I see the case before suppuration has set in.

I am, Sir, your obedient servant

Cranbrook, Oct. 1861. ThOMas BAKER, L.R. C.P.\& M.R.C.S.

\section{To the Editor of THE LANCET.}

SrR,-A case demonstrating the success of mechanical treat. ment in general anasarca appeared in THE L.i NCET of Oct. 19th, to which the following, occurring in my own practice, though differing somewhat in detail of treatment, may prove corro. borative :-

In November, 1860, I was called to see a woman, aged sixtyseven, who for some months had been suffering from general anasarca, resulting from valvular disease of the heart, accompanied by chronic bronchitis. Her difficulty of breathing was painful to witness. She was, and had been for some time, un able to assume any but a sitting posture. The dyspncea increased very rapidly in proportion as the fluid accumulated in the abdomen, \&c. She had for some time been under treat ment. After a fair trial of the usual remedies in such cases, it was determined, at a consultation with Dr. Whitby, that notwithstanding the extreme state of weakness of the patient recourse should be had to mechanical removal of the fluid. Accordingly, on the 1lth of November, I inserted a grooved needle once into the inner side of each leg, at about the junction of the middle with the lower third. Fluid commenced to trickle out freely. This was encouraged by hot fomentations, and a large quantity was thus drained off, when, at the end of three days (the patient still retaining the sitting posture), the fluid ceased to How; the acupuncture was, therefore, repeated on the 15th, and fluid continued to run in a gradually decreas. ing trickle for from fifteen to sixteen weeks, when the whole was apparently got rid of. A bandage was from the first applied to the abdomen, and carefully tightened as required for the purpose of support. The patient is now (eleven months after the operation), considering the state of her heart and lungs, in fair health, and, though unable to stand, can use her legs, which are now healed. At present there is no appearance of a return of the anasarca, and the only untoward features which have presented themselves in the treatment of this case were two or three attacks of erysipeloid inflammation.

Doubtless, any measure which tends to relieve the suffering or to prolong the life of a fellow-creature, is worthy of the attention of the profession; and in similar cases it will remain a point for the judgment of the practitioner to which of the proceedings-incision or acupuncture-he will resort.

Dr. Watson ("Principles and Practice of Physic," vol. ii., p. 711, latest edition) states, that he prefers acuunucture, and refers to the incisions as though out of date; and also to the difficulty in healing the wounds in the latter process. The effect on the system generally of either of these operations is worthy of consideration, whether the gradual and long-continued, or the quicker and shorter, proceeding affects the system most of the already debilitated patient.

Sidmouth, Oct. I aw, Sir, your obedient servant,

J. INGLeBY MI'KENzIE, M.B. Cantab.

\section{A CASE IN OBSTETRICY.} To the Editor of THE LANCET.

Sir, - I send you the particulars of a rather unusual case, which you may, perhaps, think sufficiently interesting to give a place in your journal.

Mrs. W - aged thirty, of fair complexion, sanguineous temperament, the mother of four living children, and eight months advanced in pregnancy, came under my care on the 7 th of October, for what appeared to be a slight febrile attack, attended with incessant vomiting and great nervous irritability, for which effervessing salines, with hydrocyanic acid and other sedatives, were prescribed, due attention at the same time being directed to the state of the bowels. No assignable cause could be discovered for so formidable an array of symptoms, as pain was entirely absent, and the consciouaness of the patient re. mained undisturbed during the whole period of her distress. On the evening of the 10th, my assistant, Mr. Powell, finding all the symptoms aggravated, dispatched a messenger for my assistance, and upon arriving at the patient's residence, I found her in the following condition :-Pulse 150; hurried abdominal breathing; surface of the body quite cold; the capillary system evidently at a loss; in fact, she appeared to be dying. Under these circumstances $I$ thought it prudent to call in the aid of my friend, Dr. Batty, Lecturer on Midwifery at the Liver. pool Royal Infirmary, but upon his arrival the case had as. sumed so serious an aspect, that I resolved upon immediate delivery, as the only chance left for my patient. The operation of turning I accomplished without any difficulty, and a still. born child was the result of less than a quarter of an hour's in. terference. By this time Dr. Batty arrived, and to him I handed over the remaining step of the operation-extracting the placenta. There was no hæmorrhage, and the uterus contracted well. Still there was very little improvement in the patient's condition. A full dose of Battley's sedative solution was now given, and teaspoonful doses of brandy every ten minutes. In about an hour the opium was repeated, and we left her in an apparently hopeless state, at ten o'clock, in charge of $\mathrm{my}$ assistant, who during the next eight hours administered brandy, until twelve ounces had been used. At six A.M., symptoms of reaction manifested themselves, and some bread and milk was given. A gradual improvement has since taken place, and the patient is now in a fair way of doing well.

Perhaps some of your correspondents may be able to throw a light upon the subject I have entered upon as one worthy of the consideration of the profession.

Liverpool, Oct. 1861. I am, Sir, your obedient servant,

\section{FOREIGN BODY IN THE RECTUM.} To the Editor of THE LANCET.

Sir, - T remember having read, in the "Transactions of the Pathological Society of Dublin," the account of a case by the late Sir Yhilip Crampton, resembling that in your journal of last week, communicated by Mr. Davidson, of Barking.

The case was that of a sailor, who, while on board ship, suffered severely from diarrhoa; and, obtaining no relief from medical treatment, one of his shipmates found for him a plug, consisting of two cylinders of wood-one an inch and a quarter and the other an inch in diameter; these were introduced into the rectum and forced up. The patient was thus able to go through his duties during the remainder of the voyage. When he arrived at Dublin he applied to Sir Philip Crampton, who succeeded in fastening the screw ramrod of a gun into the bottom of the plug, which was then slowly and with some difficulty extracted.

I am, Sir, yours \&c.,

Upper Montagu-street, Oet. 1861. WILLIAM O'ConNor, M.D. 